\title{
Fluid Needs for Training, Competition, and Recovery in Track-and-Field Athletes
}

\author{
Douglas J. Casa \\ University of Connecticut \\ Samuel N. Cheuvront \\ U.S. Army Research Institute of Environmental Medicine \\ Stuart D. Galloway \\ University of Stirling
}

Susan M. Shirreffs

University of St. Andrews

\begin{abstract}
The 2019 International Amateur Athletics Federation Track-and-Field World Championships will take place in Qatar in the Middle East. The 2020 Summer Olympics will take place in Tokyo, Japan. It is quite likely that these events may set the record for hottest competitions in the recorded history of both the Track-and-Field World Championships and Olympic Games. Given the extreme heat in which track-and-field athletes will need to train and compete for these games, the importance of hydration is amplified more than in previous years. The diverse nature of track-and-field events, training programs, and individuality of athletes taking part inevitably means that fluid needs will be highly variable. Track-and-field events can be classified as low, moderate, or high risk for dehydration based on typical training and competition scenarios, fluid availability, and anticipated sweat losses. This paper reviews the risks of dehydration and potential consequences to performance in track-and-field events. The authors also discuss strategies for mitigating the risk of dehydration.
\end{abstract}

Keywords: athletics, dehydration, hydration, performance, rehydration, running

Seasonal environmental changes can create unique challenges for year-long training among track-and-field athletes. However, the competitive track-and-field season is held in the summer months of the northern hemisphere and major international track-and-field competitions, such as the World Championships and the Olympic Games culminate in the hottest months of the year. The 2019 IAAF Track-and-Field World Championships will take place in Qatar in the Middle East. The 2020 Summer Olympics will take place in Tokyo, Japan. It is quite likely that these events may set the records for the hottest Track-and-Field World Championships and Olympic Games in recorded history. Serious caution is often warranted for hot-weather Olympic track-and-field events (Nielsen, 1996) and the safe preparation and conduct of competitive hot-weather exercise is of great international interest (Racinais et al., 2015). Given the extreme heat in which training and competition are likely to take place in Qatar, Tokyo, and other summer sporting venues of the future, the risks associated with dehydration could be amplified more than in previous years. This review focuses on the risks of dehydration and potential

Casa is with Korey Stringer Institute, Department of Kinesiology, University of Connecticut, Storrs, CT, USA. Cheuvront is with the U.S. Army Research Institute of Environmental Medicine, Natick, MA, USA. Galloway is with the Faculty of Health Sciences and Sport, University of Stirling, Scotland, UK. Shirreffs is with the University of St Andrews, Scotland, United Kingdom. Casa (douglas.casa@uconn. edu) is corresponding author. consequences to performance in track-and-field events. We also discuss strategies for mitigating the risk of dehydration.

The 2003 International Olympic Committee consensus conference concluded the following with regards to hydration in its consensus statement, which was recently updated in 2011 (IOC Consensus Statement, 2004; IOC Consensus Statement, 2011).

Dehydration impairs performance in most events, and athletes should be well hydrated before exercise. Sufficient fluid should be consumed during exercise to limit dehydration to less than about $2 \%$ of body mass. . . . Sodium should be included when sweat losses are high, especially if exercise lasts more than about $2 \mathrm{~h}$. Athletes should not drink so much that they gain weight during exercise. During recovery from exercise, rehydration should include replacement of both water and salts lost in sweat.

Sports nutrition, and sports hydration in particular, is a widely discussed and sometimes hotly debated topic (Cotter et al., 2014). However, several recent and comprehensive treatments on the topics of dehydration, rehydration, and sports performance buttress existing IOC conclusions (Cheuvront \& Kenefick, 2014; Evans et al., 2017; McDermott et al., 2017; Savoie et al., 2015; Wittbrodt \& Millard-Stafford, 2018). In this review, up-to-date evidence for the potential impact of dehydration on performance is described and applied to circumstances and events in track and field. Proposed 
recommendations may be used by athletes and coaches to optimize performance and health, and by governing organizations when considering the rules and regulations of the sport or the timing of events.

\section{Everyday Hydration Assessment}

Optimal hydration reflects a physical state of having normal body water and electrolytes, and it is an assumed starting point for most of the strategies and recommendations reviewed in this paper. The Venn diagram in Figure 1 is designed to simplify athlete selfassessment of day-to-day hydration status and can help ensure an optimal starting point for training and competition (Cheuvront \& Sawka, 2005). A daily loss of body weight (W) greater than 0.5 to $1.0 \mathrm{~kg}$ ( 1 to $2 \mathrm{lb}$ ), a small volume of dark colored urine (U; apple juice or darker), and the noticeable sensation of thirst (T) are all symptoms of dehydration. When two or more of these symptoms of dehydration are present, dehydration is likely. If all three markers are present, dehydration is very likely. When it is important to account for hydration status, all three WUT symptoms should be assessed upon waking each morning. If dehydration is likely or very likely, greater attention should be given to 24-hr fluid and electrolyte intakes. The use of WUT helps to establish deviations from an optimal hydration baseline and becomes increasingly important when track-and-field athletes travel to locations with warmer weather or higher terrestrial elevations, both of which can increase body water losses beyond normal. Travel to locations with limited potable water availability also requires extra attention to water planning and make WUT a useful tool for establishing the adequacy of daily fluid intakes. More advanced hydration assessment techniques are unlikely to be implemented in competition but are possible in advanced training venues. The interested reader can also consult Maughan and Shirreffs (2008) for practical hydration assessment guidance or Armstrong and Casa (2009) for the application of more advanced assessment methods.

\section{Basic Sweat Science}

Physical activity requires the use of stored energy to perform work. In the process, significant body heat is generated. Were it not for

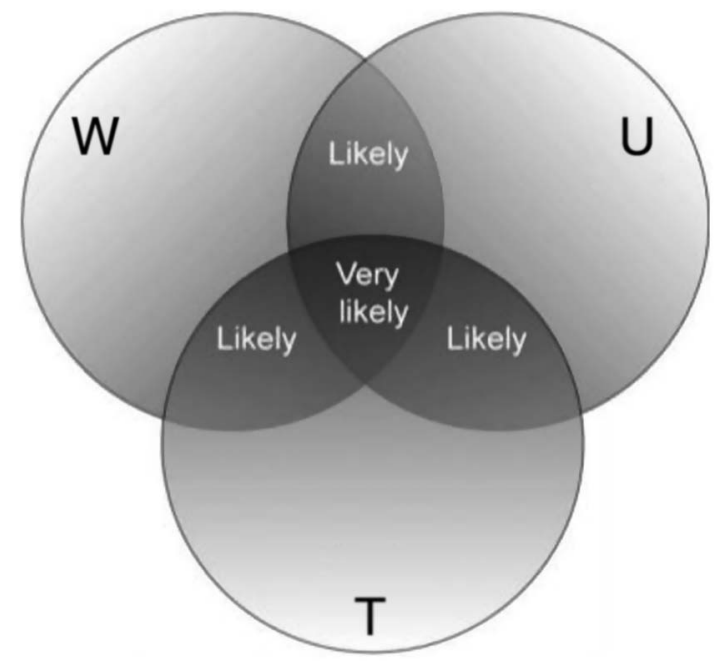

Figure 1 - The Venn diagram for athlete self-assessment of day-to-day hydration status (Cheuvront \& Sawka, 2005). If two or more of the signs ( $\mathrm{W}=$ reduced body weight, $\mathrm{U}=$ dark urine color, and $\mathrm{T}=$ feeling thirsty) are present, then correction of fluid balance is required. heat loss mechanisms, a $60-\mathrm{kg}$ runner racing $10 \mathrm{~km}$ at $27-\mathrm{min}$ finishing pace would collapse from a lethal body temperature after only 3.2 km (Dennis \& Noakes, 1999; Nielsen, 1996). In weather that is temperate or warmer, sweating accounts for more than $50 \%$ of body heat removal and close to $100 \%$ in very hot environments (Gagge \& Gonzalez, 1996). Millions of sweat glands become activated in response to exercise and the evaporation of sweat from the skin carries away heat. In fact, the evaporation of $1 \mathrm{~L}$ of sweat from the skin surface can carry away $83 \%$ of the heat produced during a $27-\mathrm{min} 10-\mathrm{km}$ race (Wenger, 1972).

The primary factors that influence total sweat loss (L; Sweating Rate $\times$ Time) include body size, exercise intensity, exercise duration, the environment, and choice of clothing. These factors explain more than $90 \%$ of the widely different sweat losses expected among athletes (Gagnon et al., 2013). Widely different factors among different track-and-field athletes easily explain why observed athlete sweating rates can range from 0.5 to $3.0 \mathrm{~L} / \mathrm{hr}$ (Baker et al., 2016). Typical fluid needs for adults range from 2 to $4 \mathrm{~L} /$ day (Sawka et al., 2005) and function to replace obligatory losses and dilute metabolic and dietary waste products (Cheuvront \& Kenefick, 2016). A typical 2-hr/day track-and-field training session could, therefore, increase daily fluid needs by 1 to $6 \mathrm{~L} /$ day due to the range of anticipated sweat losses. Electrolyte losses in sweat (sodium and potassium) amount to about $1 \mathrm{~g} / \mathrm{L}$ (assuming $50 \mathrm{mmol} / \mathrm{L}$ ) (Baker et al., 2016), which at the low end is replaced by habitual dietary practices, but at the upper end could require special attention to food electrolyte intakes (Maughan \& Shirreffs, 2008). At minimum, track-and-field athletes must replace body water and electrolyte losses daily. Failure to do so can lead to dehydration, poor training, and competition outcomes.

\section{Potential Body Water Balance Concerns for Track- and-Field Athletes}

Table 1 provides a composite picture of qualitative dehydration risk by track-and-field event categories using sweat losses and fluid availability in training and competition. The table also summarizes the risk that dehydration, if present or accrued, would negatively affect performance. The table is meant as a guide for a discussion of event-specific risks only. Individual athletes are encouraged to personalize their fluid intake practices (see "Strategies to Optimize Hydration" section).

\section{Low-Risk Events}

Track-and-Field events with a low-dehydration risk include jumping (with exceptions), throwing, sprints, and multi-events. The principle reasons for low risk are the types of training performed (e.g., strength, power), the generally unlimited availability of fluids in both training and competitions, and the small effects that dehydration has on these types of performance even when present. Although there are no published data on sweating rates in low-risk track-and-field events, it is anticipated that losses would be lowest in these events because explosive events like these generate tremendous heat for only very short periods followed by significant rest breaks both in training (between sets) and competition (between rounds). For example, Watson et al. (2005) monitored sweat volume losses in simulated sprint sessions. In these sessions, the subjects, who were experienced but not elite sprinters, warmed up for 15 min then ran either a 50- and 200-m sprint separated by 40 min or undertook vertical jumps and a 400-m sprint. Each of these sessions was undertaken twice. The body mass reductions 
Table 1 Potential Body Water Balance Concerns for Track-and-Field athletes

\begin{tabular}{|c|c|c|c|c|c|c|c|c|}
\hline \multirow[b]{2}{*}{ Event } & \multicolumn{2}{|c|}{ Sweat losses ${ }^{a}$} & \multicolumn{2}{|c|}{ Availability of fluids } & \multicolumn{2}{|c|}{ Risk of dehydration } & \multicolumn{2}{|c|}{ Performance risk } \\
\hline & Training & Competition & Training & Competition & Training & Competition & Training & Competition \\
\hline $\begin{array}{l}\text { Jumping (high jump, } \\
\text { long jump, triple jump, } \\
\text { and pole vault) }\end{array}$ & Mod & Low & High & High & Low & Low $^{b}$ & Low & Low \\
\hline $\begin{array}{l}\text { Throwing (shot put, javelin, } \\
\text { and discus) }\end{array}$ & Mod & Low & High & High & Low & Low & Low & Low \\
\hline Sprints $(<800 \mathrm{~m})$ & Mod & Low & High & High & Low & Low & Low & Low \\
\hline $\begin{array}{l}\text { Middle-distance running } \\
(800 \mathrm{~m} \text { to } 10 \mathrm{~km})\end{array}$ & High & Low & Mod & Low & Mod & Low & Mod & High \\
\hline $\begin{array}{l}\text { Long-distance } \\
\text { running/walking (>10 km) }\end{array}$ & High & High & Low & Low & High & High & High & High \\
\hline Multievents (decathlon) & High & Mod & High & High & Low & Low & Low & Low \\
\hline
\end{tabular}

averaged 0.8 and $1.3 \mathrm{~kg}$ in the 50/200-m sessions over a 2-hr period, and averaged 0.5 and $1.1 \mathrm{~kg}$ over $45 \mathrm{~min}$ in the $400 \mathrm{~m}$ and vertical jump session. These reductions are equivalent to approximately $1-1.5 \%$ of the athletes' body mass and easily replaceable during the training session.

Jumping performance has frequently been investigated as a means of assessing the influence of a body water loss on muscle power: jump power and jump height have been most frequently measured (Cheuvront et al., 2010; Gutiérrez et al., 2003; Hoffman et al.,1995; Kraemer et al., 2001; Viitasalo at al., 1987; Watson et al., 2005). In theory, intentional dehydration might be desired to try and improve jumping performance by virtue of being "lighter." In fact, if dehydration did not impair muscle force production in any way, then jump height improvements should reflect the level of dehydration (i.e., $1 \%$ dehydration should improve jump height by $1 \%$ ) (see appendix in Cheuvront et al., 2010). The majority of studies investigating the effects of dehydration on jump performance have used between $1 \%$ and $4 \%$ dehydration (Cheuvront et al., 2010; Gutiérrez et al., 2003; Hoffman et al., 1995; Watson et al., 2005) although a $6 \%$ body mass loss has been investigated when energy restriction has been combined with dehydration (Kraemer et al., 2001; Viitasalo et al., 1987). Yet the majority of these studies have found no significant effect of the body mass reduction on jumping power or height. When Cheuvront et al. (2010) replaced the water lost as weight worn ergonomically as a vest, jump performance decreased when dehydrated. This suggests that the benefits of being lighter when dehydrated are masked by the detrimental effects of dehydration on muscle function. When the effects are combined, there are no "measurable" effects on performance.

The conclusion that dehydration impairs some aspect(s) of strength or power is cautionary for throwing events, which rely heavily on strength and power. Indeed, two systematic reviews and one meta-analysis summarizing the effects of dehydration on muscle strength, power, and high-intensity anaerobic capacity (Cheuvront \& Kenefick, 2014; Judelson et al., 2007; Savoie et al., 2015) determined that dehydration can impair strength and power. However, it was concluded that a significant loss of body water (3-4\% body mass) was required to produce small, but significant effects on performance. Although small effects remain of utmost importance in elite sports (Hopkins et al., 1999), the risk of achieving 3-4\% dehydration in sprinting, jumping, and throwing events is very low. Therefore, the risks to performance are also low (Table 1). As a result, the main concern for hydration in low- risk track-and-field events is to ensure that training and competition are begun in a state of optimal hydration. This is especially true for multi-event track-and-field athletes who may be competing for many hours, but with ample opportunities for rest and rehydration.

\section{Moderate-Risk Events}

The middle distances for running ( $800 \mathrm{~m}$ to $3 \mathrm{~km}$ ) and some longdistance running events $(5-10 \mathrm{~km})$ may be considered track-andfield events with moderate risk for dehydration. Although the risk of dehydration is low in the events themselves due to their short durations $(<2$ to $<30 \mathrm{~min})$, moderate risk for these events stems from daily high and sustained sweat losses which could carry over to negatively affect training and performance from day-to-day. Fluid availability may also be high (e.g., track training) or low (road training), depending on the training season or phase of training. Moderate risk middle and long-distance running events in track and field are all contested entirely on a track. Therefore, as for the sprints, the duration of the races are short enough to preclude fluid being taken during the events and too short for significant dehydration to develop during the race, even when sweating rates are very high. As with low-risk events, the main concern for hydration in low-risk track-and-field events is to ensure that training and competition are begun in a state of optimal hydration. However, given the endurance and interval training frequently undertaken by these athletes, the volumes of sweat that may be lost and the likelihood that drinking during training may frequently be limited for logistical or stomach comfort reasons, dehydration during training for many middle and long distance runners may be a common scenario. Deliberate rehydration strategies (see "Basic Rehydration Science" section) may become necessary when a significant portion of the training has yet to take place, particularly when the desire is to complete a high-quality training session with a "performance" element to it. The negative effects of dehydration on the energy system relied upon for competitive middle and long-distance running is discussed below.

\section{High-Risk Events}

Long-distance running and walking events $(20-50 \mathrm{~km})$ may be considered track-and-field events with a high risk for dehydration. In comparison to the other track-and-field events, there has been a considerable amount of both descriptive research into sweat losses 
of runners during at least some of the long-distance events (in particular, the marathon) and also intervention studies investigating the effects of dehydration on endurance exercise performance. Training involves many hours of running and walking where fluid availability/support must be planned in advance. During competitions, fluid availability is minimal and the intensity of exercise may make it difficult to prevent progressive dehydration from occurring, particularly late in a competition when high levels of performance are required. Indeed, dehydration to levels well beyond those associated with impaired performance ( $>2 \%$ of body mass) has been consistently reported at the finish of marathon races (Cheuvront \& Haymes, 2001).

The effects of dehydration on endurance running or walking performance must be viewed through the lens of both laboratory and field studies of endurance "exercise." The mode of test activity is often not running or walking and the caliber of athlete tested is rarely elite. However, research outcomes are interpreted using the same aerobic energy system, and the knowledge that human performance responses to stressors such as environmental heat vary only by degree when comparing elite and recreational runners (Ely et al., 2008) or when comparing laboratory outcomes to field observations (Casa et al., 2010), which permits reasonable extrapolation of results.

Cheuvront and Kenefick (2014) reviewed 34 studies conducted between 1961 and 2012 investigating the effects of dehydration on endurance exercise performance. Of the 60 total performance observations, 41 (68\%) showed a statistically significantly impairment in performance when dehydrated and 12 more $(88 \%)$ reported an overall group decrement in performance that did not reach statistical significance. These findings are more impressive still when one considers that most studies are undertaken with the minimal number of test volunteers necessary to find statistical significance. Cheuvront and Kenefick (2014) concluded that dehydration $\geq 2 \%$ of body mass impairs endurance exercise performance as measured primarily by a shortened time to exhaustion or reduction in sustainable exercise intensity. Importantly, the effect is magnified in warmer environmental temperatures (Kenefick et al., 2010). In addition, partial rehydration has been shown to dramatically enhance performance and physiological function during running in the heat, and the effect is exacerbated if the exercise is intense (Casa et al., 2010; Lopez et al., 2016). Whether programmed or thirst-driven drinking strategies are more successful depends highly on the circumstances of the training and competition (Kenefick, 2018). A more detailed discussion of this topic follows (see "Strategies for Optimizing Hydration" section). So long as dehydration is limited to $<2 \%$ of body mass, performance is likely to be sustainable in all track-and-field events.

\section{Dehydration and Mental Readiness}

The potential effects of dehydration on brain function could impact track-and-field athlete performance by interfering with one or more aspects of concentration or motivation. It is widely and consistently reported that dehydration has a negative effect on mood state through one or more alterations in perceived tiredness, alertness, confusion, fatigue, anger, or depression (Cheuvront \& Kenefick, 2014). When dehydration is $\geq 2 \%$ body mass, it can also produce unpleasant and distractive symptoms, such as dry mouth, thirst, and headache (Cheuvront \& Kenefick, 2014).

A meta-analysis by Wittbrodt and Millard-Stafford (2018) examined the impact of dehydration on cognitive performance from 33 studies that included more than 400 test subjects. Wide variability was observed among studies, but the authors concluded that dehydration $\geq 2 \%$ body mass produced a small, but statistically significant impairment in cognitive performance tasks involving attention, executive function, and motor coordination (Wittbrodt \& Millard-Stafford, 2018). As $\geq 2 \%$ dehydration appears to describe both physical and mental performance thresholds, it is likely that the risks to attention, executive function, and motor coordination are primarily for high-risk track-and-field events that rely little on the mental performance measures affected.

\section{Basic Rehydration Science}

Sweat is composed primarily of water $(\sim 99.9 \%)$. Although sweat electrolyte losses can require special attention to dietary replacement (see "Basic Sweat Science" section), most fluids are consumed with meals and most meals generally provide ample replacement of sweat electrolytes, particularly when energy consumption matches energy utilization. However, when flavor is desired, timing between meals is uncertain or extended, or training/competition is anticipated to be intense and prolonged, a typical sports drink formulation can provide energy (4-6\% carbohydrate), contribute to the replacement of the electrolytes lost in sweat (20 mmol/L sodium; $4 \mathrm{mmol} / \mathrm{L}$ potassium), and generally be absorbed faster than water alone (Baker \& Jeukendrup, 2014; Leiper, 2015). For all track-and-field athletes, optimal rehydration may best be sustained between training days by behaviorallydriven ingestion of solid food and water (Maughan et al., 1996). However, between training sessions or events, beverages that contain macronutrients or electrolytes are better retained than water and should be considered (Maughan et al., 2016, 2018; Shirreffs et al., 1996; Sollanek et al., 2018).

\section{Strategies for Optimizing Hydration}

It is clear that for all track-and-field events, optimal day-to-day hydration is most important for optimizing training and competition. The concepts reviewed in Figure 1 are a simple but effective starting point for success. Other simple (Maughan \& Shirreffs, 2008) and more advanced techniques (Armstrong \& Casa, 2009) may also be adopted. For low- and moderate-risk track-and-field events, the daily use of Figure 1 and the use of thirst to guide drinking behavior is probably sufficient for optimizing hydrationparticularly when training and competing in familiar settings and when there is no limit to food or fluid access (Kenefick, 2018). But when training or competing in high-risk events-particularly when in unfamiliar settings or when access to food and fluid may be limited, then a more programmed approach centered around knowledge of personal sweat losses is recommended (Cheuvront \& Kenefick, 2017; Kenefick, 2018).

Track-and-Field athletes train as they intend to compete; fluid replacement planning should be part of the strategy. For example, in a marathon race, drink stations are positioned at regular intervals. The absence of water stations during long training runs means implementing a drinking strategy by other means, such as with wearable drink systems. A simple strategy such as this can accustom gastric tolerance and optimize hydration for the most difficult training sessions. It appears that while $>90 \%$ of IAAF athletes have a fluid intake plan when competitions are forecasted to be hot, the volumes planned may or may not reflect anticipated losses (Périard et al., 2017).

The flip side of replacing sweat losses is to minimize sweat losses so that less drinking is needed. Various kinds of thermal management scenarios are possible, such as cold towels, ice vests, indoor (air conditioned) exercise, and early morning- or lateevening exercise. Ingestion of ice slurry before exercise is an 
Table 2 Practical Strategies to Reduce Dehydration for Track-and-Field Athletes

\begin{tabular}{|c|c|}
\hline Strategy & Details \\
\hline WUT & $\begin{array}{l}\text { First morning weight, urine color, and thirst sensation to guide day-to-day adequacy of water and electrolyte } \\
\text { consumption. }\end{array}$ \\
\hline Incorporate electrolytes & Rehydrate with meals and include sodium and potassium-rich foods. \\
\hline Personalize fluid needs & Estimate personal sweat losses from changes in body weight pre- to postexercise. \\
\hline Train as you compete & $\begin{array}{l}\text { Incorporate a competition drinking strategy into training (e.g., using wearable drinking systems as a } \\
\text { substitute for water stations). }\end{array}$ \\
\hline Improve thermal management & $\begin{array}{l}\text { Train during the coolest times of day }{ }^{\mathrm{a}} \text {; consider indoor air-conditioned training in extreme heat; and consider use } \\
\text { of active cooling (e.g., cold towels, cold showers). }\end{array}$ \\
\hline
\end{tabular}

Note. $\mathrm{W}=$ reduced body weight; $\mathrm{U}=$ dark urine color; $\mathrm{T}=$ feeling thirsty. ${ }^{\mathrm{a}}$ Except when deliberate heat acclimatization is desired.

alternative hydration strategy, but appears no more effective than cold water and may produce untoward side effects (Jay \& Morris, 2018). The practice of trying to delay dehydration by expanding total body water using beverages with high salt concentrations or glycerol is generally ineffective and carries its own risks (McDermott et al., 2017). Approximately $50 \%$ of IAAF athletes practice some form of thermal management before hot weather competitions (Périard et al., 2017). Table 2 summarizes strategies for optimizing hydration.

\section{Summary}

The impact of dehydration on training and performance outcomes in athletes remains a much-debated topic. Track-and-field athletes often train and compete in hot environmental conditions, where fluid balance and hydration become essential daily considerations. Given the individual nature of sweating responses with training and competition, each athlete should assess their own individual fluid requirements and determine if these are likely to be a cause for concern (e.g., if $>2 \%$ body mass loss observed). The risk of impairment in training or performance with levels of dehydration of $<2 \%$ body mass loss is "low" and applies to many track-and-field events (particularly sprints, jumps, and throws). However, other Track and Field events carry a "high" risk, typically in the longer duration and continuous activities, such as endurance events. For these events, careful attention should be placed on individualized and planned hydration practices to optimize training and performance outcomes.

\section{Acknowledgments}

The authors would like to offer our sincerest gratitude to Robert Carter, who was an author on the original manuscript. In addition, they are grateful for the assistance of Yasuki Sekiguchi, a doctoral student at the University of Connecticut in the USA for his assistance with some technical aspects of this publication. The opinions or assertions contained herein are the private views of the authors and should not be construed as official or reflecting the views of the Army or the Department of Defense. Approved for public release: distribution unlimited.

\section{References}

Armstrong, L.E., \& Casa, D.J. (2009). Methods to evaluate electrolyte and water turnover of athletes. Athletic Training and Sports Health Care, 1(4), 169-179. doi:10.3928/19425864-20090625-06

Baker, L.B., Barnes, K.A., Anderson, M.L., Passe, D.H., \& Stofan, J.R. (2016). Normative data for regional sweat sodium concentration and whole-body sweating rate in athletes. Journal of Sports Sciences, 34(4), 358-368. PubMed ID: 26070030 doi:10.1080/02640414.2015.1055291
Baker, L.B., \& Jeukendrup, A.E. (2014). Optimal composition of fluidreplacement beverages. Comprehensive Physiology, 4(2), 575-620. PubMed ID: 24715561 doi:10.1002/cphy.c130014

Casa, D.J., Stearns, R.L., Lopez, R.M., Ganio, M.S., McDermott, B.P., Walker Yeargin, S., . . Maresh, C.M. (2010). Influence of hydration on physiological function and performance during trail running in the heat. Journal of Athletic Training, 45(2), 147-156. PubMed ID: 20210618 doi:10.4085/1062-6050-45.2.147

Cheuvront, S.N., \& Haymes, E.M. (2001). Thermoregulation and marathon running: biological and environmental influences. Sports Medicine, 31(10), 743-762. doi:10.2165/00007256-200131100-00004

Cheuvront, S.N., \& Kenefick, R.W. (2014). Dehydration: Physiology, assessment, and performance effects. Comprehensive Physiology, 4(1), 257-285. PubMed ID: 24692140 doi:10.1002/cphy.c130017

Cheuvront, S.N., \& Kenefick, R.W. (2016). Am I drinking enough? Yes, no, and maybe. Journal of the American College of Nutrition, 35(2), 185192. PubMed ID: 26885571 doi:10.1080/07315724.2015.1067872

Cheuvront, S.N., \& Kenefick, R.W. (2017). CORP: Improving the status quo for measuring whole body sweat losses. Journal of Applied Physiology, 123(3), 632-636. doi:10.1152/japplphysiol.00433. 2017

Cheuvront, S.N., Kenefick, R.W., Ely, B.R., Harman, E.A., Castellani, J.W., Frykman, P.N., ... Sawka, M.N. (2010). Hypohydration reduces vertical ground reaction impulse but not jump height. European Journal of Applied Physiology, 109(6), 1163-1170. PubMed ID: 20379829 doi:10.1007/s00421-010-1458-y

Cheuvront, S.N., \& Sawka, M.N. (2005). Hydration assessment of athletes. Gatorade Sports Science Institute, 18(2), 1-5.

Cotter, J.D., Thornton, S.N., Lee, J.K., \& Laursen, P.B. (2014). Are we being drowned in hydration advice? Thirsty for more? Extreme Physiology \& Medicine, 3(1), 18. PubMed ID: 25356197 doi:10. 1186/2046-7648-3-18

Dennis, S.C., \& Noakes, T.D. (1999). Advantages of a smaller bodymass in humans when distance-running in warm, humid conditions. European Journal of Applied Physiology and Occupational Physiology, 79(3), 280-284. PubMed ID: PubMed ID: 10048634

Ely, M.R., Martin, D.E., Cheuvront, S.N., \& Montain, S.J. (2008). Effect of ambient temperature on marathon pacing is dependent on runner ability. Medicine \& Science in Sports \& Exercise, 40(9), 1675-1680. doi:10.1249/MSS.0b013e3181788da9

Evans, G.H., James, L.J., Shirreffs, S.M., \& Maughan, R.J. (2017). Optimizing the restoration and maintenance of fluid balance after exercise-induced dehydration. Journal of Applied Physiology, 122(4), 945-951. doi:10.1152/japplphysiol.00745.2016

Gagge, A.P., \& Gonzalez, R.R. (1996). Mechanisms of heat exchange: Biophysics and physiology. In: M.J. Fregly \& C.M. Blatteis (Eds.), Handbook of physiology: Environmental physiology (pp. 45-84). Bethesda, MD: American Physiological Society. 
Gagnon, D., Jay, O., \& Kenny, G.P. (2013). The evaporative requirement for heat balance determines whole-body sweat rate during exercise under conditions permitting full evaporation. The Journal of Physiology, 591(11), 2925-2935. PubMed ID: 23459754 doi:10.1113/ jphysiol.2012.248823

Gutiérrez, A., Mesa, J.L.M., Ruiz, J.R., Chirosa, L.J., \& Castillo, M.J. (2003). Sauna-induced rapid weight loss decreases explosive power in women but not in men. International Journal of Sports Medicine, 24(7), 518-522. doi:10.1055/s-2003-42017

Hoffman, J.R., Stavsky, H., \& Falk, B. (1995). The effect of water restriction on anaerobic power and vertical jumping height in basketball players. International Journal of Sports Medicine, 16(4), 214-218. PubMed ID: 7657413 doi:10.1055/s-2007-972994

Hopkins, W.G., Hawley, J.A., \& Burke, L.M. (1999). Design and analysis of research on sport performance enhancement. Medicine \& Science in Sports \& Exercise, 31(3), 472-485. doi:10.1097/00005768199903000-00018

IOC consensus statement on sports nutrition 2003. (2004). Journal of Sports Sciences, 22(1).

IOC consensus statement on sports nutrition 2010. (2011). Journal of Sports Sciences, 29(Suppl. 1), S3-S4. doi:10.1080/02640414.2011.619349

Jay, O., \& Morris, N.B. (2018). Does cold water or ice slurry ingestion during exercise elicit a net body cooling effect in the heat? Sports Medicine, 48(Suppl. 1), 17-29. doi:10.1007/s40279-017-0842-8

Judelson, D.A., Maresh, C.M., Anderson, J.M., Armstrong, L.E., Casa, D.J., Kraemer, W.J., \& Volek, J.S. (2007). Hydration and muscular performance: Does fluid balance affect strength, power and highintensity endurance? Sports Medicine, 37(10), 907-921. doi:10.2165/ 00007256-200737100-00006

Kenefick, R.W. (2018). Drinking strategies: Planned drinking versus drinking to thirst. Sports Medicine, 48(Suppl. 1), 31-37. doi:10. 1007/s40279-017-0844-6

Kenefick, R.W., Cheuvront, S.N., Palombo, L.J., Ely, B.R., \& Sawka, M.N. (2010). Skin temperature modifies the impact of hypohydration on aerobic performance. Journal of Applied Physiology, 109(1), 79-86. doi:10.1152/japplphysiol.00135.2010

Kraemer, W.J., Fry, A.C., Rubin, M.R., Triplett-McBride, T., Gordon, S.E., Koziris, L.P., ... Fleck, S.J. (2001). Physiological and performance responses to tournament wrestling. Medicine \& Science in Sports \& Exercise, 33(8), 1367-1378. doi:10.1097/00005768200108000-00019

Leiper, J.B. (2015). Fate of ingested fluids: Factors affecting gastric emptying and intestinal absorption of beverages in humans. Nutrition Reviews, 73(Suppl. 2), 57-72. doi:10.1093/nutrit/nuv032

Lopez, R.M., Casa, D.J., Jensen, K.A., Stearns, R.L., DeMartini, J.K., Pagnotta, K.D., ... Maresh, C.M. (2016). Comparison of two fluid replacement protocols during a $20-\mathrm{km}$ trail running race in the heat. Journal of Strength \& Conditioning Research, 30(9), 2609-2616. doi:10.1519/JSC.0000000000001359

Maughan, R.J., Leiper, J.B., \& Shirreffs, S.M. (1996). Restoration of fluid balance after exercise-induced dehydration: effects of food and fluid intake. European Journal of Applied Physiology and Occupational Physiology, 73(3-4), 317-325. PubMed ID: 8861691 doi:10.1007/ BF02425493

Maughan, R.J., \& Shirreffs, S.M. (2008). Development of individual hydration strategies for athletes. International Journal of Sport Nutrition and Exercise Metabolism, 18(5), 457-472. PubMed ID: PubMed ID: 19033609 doi:10.1123/ijsnem.18.5.457

Maughan, R.J., Watson, P., Cordery, P.A., Walsh, N.P., Oliver, S.J., Dolci, A., ... Galloway, S.D. (2016). A randomized trial to assess the potential of different beverages to affect hydration status: Development of a beverage hydration index. The American Journal of Clinical Nutrition, 103(3), 717-723. PubMed ID: 26702122 doi:10.3945/ajcn.115.114769

Maughan, R.J., Watson, P., Cordery, P.A., Walsh, N.P., Oliver, S.J., Dolci, A., ... Galloway, S.D. (2018). Sucrose and sodium but not caffeine content influence the retention of beverages in humans under euhydrated conditions. International Journal of Sport Nutrition and Exercise Metabolism,29(12), 51-60. doi:10.1123/ijsnem.2018-0047

McDermott, B.P., Anderson, S.A., Armstrong, L.E., Casa, D.J., Cheuvront, S.N., Cooper, L., ... Roberts, W.O. (2017). National Athletic Trainers' Association position statement: Fluid replacement for the physically active. Journal of Athletic Training, 52(9), 877-895. PubMed ID: 28985128 doi:10.4085/1062-6050-52.9.02

Nielsen, B. (1996). Olympics in Atlanta: A fight against physics. Medicine \& Science in Sports \& Exercise, 28(6), 665-668. doi:10.1097/ 00005768-199606000-00004

Périard, J.D., Racinais, S., Timpka, T., Dahlström, Ö., Spreco, A., Jacobsson, J., ... Alonso, J.-M. (2017). Strategies and factors associated with preparing for competing in the heat: A cohort study at the 2015 IAAF World Athletics Championships. British Journal of Sports Medicine, 51(4), 264-270. PubMed ID: 27815238 doi:10. 1136/bjsports-2016-096579

Racinais, S., Alonso, J.M., Coutts, A.J., Flouris, A.D., Girard, O., González-Alonso, J., . . Périard, J.D. (2015). Consensus recommendations on training and competing in the heat. British Journal of Sports Medicine, 49(18), 1164-1173. PubMed ID: 26069301 doi:10. 1136/bjsports-2015-094915

Savoie, F.-A., Kenefick, R.W., Ely, B.R., Cheuvront, S.N., \& Goulet, E.D.B. (2015). Effect of hypohydration on muscle endurance, strength, anaerobic power and capacity and vertical jumping ability: A meta-analysis. Sports Medicine, 45(8), 1207-1227. doi:10.1007/ s40279-015-0349-010.1007/s40279-015-0349-0

Sawka, M.N., Cheuvront, S.N., \& Carter, R. (2005). Human water needs. Nutrition Reviews, 63(6 Pt 2), S30-S39. PubMed ID: 16028570 doi:10.1111/j.1753-4887.2005.tb00152.x

Shirreffs, S.M., Taylor, A.J., Leiper, J.B., \& Maughan, R.J. (1996). Postexercise rehydration in man: effects of volume consumed and drink sodium content. Medicine \& Science in Sports \& Exercise, 28(10), 1260-1271. doi:10.1097/00005768-199610000-00009

Sollanek, K.J., Tsurumoto, M., Vidyasagar, S., Kenefick, R.W., \& Cheuvront, S.N. (2018). Neither body mass nor sex influences beverage hydration index outcomes during randomized trial when comparing 3 commercial beverages. The American Journal of Clinical Nutrition, 107(4), 544-549. PubMed ID: 29635499 doi:10.1093/ajcn/nqy005

Viitasalo, J.T., Kyröläinen, H., Bosco, C., \& Alen, M. (1987). Effects of rapid weight reduction on force production and vertical jumping height. International Journal of Sports Medicine, 8(4), 281-285. PubMed ID: 3667026 doi:10.1055/s-2008-1025670

Watson, G., Judelson, D.A., Armstrong, L.E., Yeargin, S.W., Casa, D.J., \& Maresh, C.M. (2005). Influence of diuretic-induced dehydration on competitive sprint and power performance. Medicine \& Science in Sports \& Exercise, 37(7), 1168-1174. doi:10.1249/01.mss. 0000170100.93279.be

Wenger, C.B. (1972). Heat of evaporation of sweat: Thermodynamic considerations. Journal of Applied Physiology, 32(4), 456-459. PubMed ID: 5026491 doi:10.1152/jappl.1972.32.4.456

Wittbrodt, M.T., \& Millard-Stafford, M. (2018). Dehydration impairs cognitive performance: A meta-analysis. Medicine \& Science in Sports \& Exercise,50(11), 2360-2368. doi:10.1249/MSS.0000000000001682 